\author{
Y. H. Hamid · S. A. Urhammer · C. Glümer • \\ K. Borch-Johnsen · T. Jørgensen · T. Hansen • \\ O. Pedersen
}

\title{
The common T60N polymorphism of the lymphotoxin- $\alpha$ gene is associated with type 2 diabetes and other phenotypes of the metabolic syndrome
}

Received: 21 April 2004 / Accepted: 4 October 2004 / Published online: 24 February 2005

(C) Springer-Verlag 2005

\begin{abstract}
Aims/hypothesis: Associations between variations in the lymphotoxin- $\alpha$ gene (LTA) and myocardial infarction, cerebral infarction and type 1 diabetes have previously been reported. We hypothesised that, in its homozygous form, the functional T60N variant of LTA is associated with type 2 diabetes and other features of the metabolic syndrome among Danish Caucasian individuals. Methods: The T60N polymorphism of LTA was genotyped in the population-based Inter99 study cohort (6,514 Caucasian subjects) and in a group of type 2 diabetic patients by analysis of PCR-generated primer extension products using highthroughput chip-based matrix-assisted laser desorption/ ionisation time-of-flight mass spectronomy. Results: Comparison of 1,401 diabetic patients with 1,470 matched glucosetolerant control subjects from the Inter99 cohort revealed that the frequency of the mutant at codon 60 in its homozygous
\end{abstract}

The Steno Diabetes Center, a hospital that provides services for the Danish health care system, is owned by the pharmaceutical company Novo Nordisk (Bagsvaerd, Denmark). Parts of the research carried out at the Steno Diabetes Center are funded through unrestricted grants from this company. K. Borch-Johnsen, T. Hansen and O. Pedersen are individual shareholders in Novo Nordisk.

Y. H. Hamid · S. A. Urhammer · C. Glümer ·

K. Borch-Johnsen · T. Hansen · O. Pedersen

Steno Diabetes Center and Hagedorn Research Institute,

Gentofte, Denmark

C. Glümer · T. Jørgensen

Research Centre for Prevention and Health,

Glostrup University Hospital,

Glostrup, Denmark

K. Borch-Johnsen · O. Pedersen

Faculty of Health Science, University of Aarhus,

Aarhus, Denmark

Y. H. Hamid $(\bowtie)$

Steno Diabetes Center,

Niels Steensens Vej 2,

2820 Copenhagen, Gentofte, Denmark

e-mail: yah@steno.dk

Tel.: +45-4443-7324

Fax: $+45-4443-8234$ form ( $N / N$ genotype $)$ was higher among the diabetic patients than among the control subjects $(14.6 \%$ [95\% CI 12.8-16.5] vs $12.0 \%$ [95\% CI 10.3-13.7], $p=0.048$; odds ratio $=1.24$ ). This association was even stronger among the 131 patients with early-onset (diagnosis at 40 years or younger) diabetes (21.4\% [95\% CI 14.4-28.4] vs $12.0 \%$ [95\% CI 10.3-13.7], $p=0.004$; odds ratio $=1.99$ ). Additionally, studies of the metabolic syndrome (as defined by the 1999 World Health Organization criteria) in the Inter99 study cohort revealed that the frequency of the N/N LTA genotype was higher among subjects presenting one or more features of the metabolic syndrome $(n=4,425)$ than among subjects with no characteristics of this syndrome $(n=1,752)(p=0.026)$. Conclusions/ interpretation: The T60N LTA polymorphism is associated with type 2 diabetes and other features of the metabolic syndrome among Caucasian individuals.

Keywords Early-onset type 2 diabetes $\cdot$ Genetics $\cdot$ Inter99 study IVS1+90ag polymorphism - LTA $\cdot$ Lymphotoxin · Metabolic syndrome $\cdot N c o$ I polymorphism $\cdot T 26 N$ polymorphism $\cdot$ T60N polymorphism $\cdot T N F-\beta$

Abbreviations HOMA-IR: Homeostasis model assessment of insulin resistance - LADA: Latent autoimmune diabetes in adults - LTA: lymphotoxin- $\alpha$. MAF: Minor allele frequency $\cdot$ OR: odds ratio $\cdot$ SNP: Single-nucleotide polymorphism - WHO: World Health Organization

\section{Introduction}

Lymphotoxin- $\alpha$ (LTA), previously known as TNF- $\beta$, is a proinflammatory cytokine primarily produced by lymphocytes that is known to play multiple roles in the regulation of the immune system and inflammatory reactions $[1,2]$. The genes that encode LTA and TNF- $\alpha$ are structurally comparable. The last exon of $L T A$, which encodes more than $80 \%$ of the secreted protein, shares $56 \%$ sequence homology with TNF- $\alpha$ [3]. Furthermore, the homotrimeric form of LTA binds to the TNF- $\alpha$ receptor [4]. 
Several variants of LTA have been described, including an IVS1+90ag polymorphism in the first intron, referred to as $N c o$ I [5] or $+252 \mathrm{~A} / \mathrm{G}$ in other reports [6]. This singlenucleotide polymorphism (SNP) is in tight linkage disequilibrium with another polymorphism, T60N (also called $\mathrm{T} 26 \mathrm{~N}$ in some reports), that results in the substitution of a threonine residue with an asparagine residue at codon 60 in exon $3[6,7]$. The $A$ allele at the intron position reduces LTA production [5] and increases $T N F-\alpha$ expression in vitro [7]. Other in vitro experiments have shown that the T60N polymorphism is associated with a twofold increase in the induction of cell-adhesion molecules in the vascular smooth muscle cells of human coronary arteries. Furthermore, the IVS1+90ag variant influences the transcriptional activity of $L T A$, indicating that an unknown nuclear factor (s) is involved in regulating the transcription of LTA [6].

$L T A$ is located close to $T N F-\alpha$ within the class III region of the HLA complex on the short arm of chromosome 6 $[8,9]$. This chromosomal region, which harbours many genes that encode proteins involved in critical immune functions, represents the chromosomal locus with the strongest known contribution to susceptibility to type 1 diabetes and has been designated the name IDDM1 [10, 11]. Interestingly, LTA is one of the genes in this region that has been implicated in the pathogenesis of type 1 diabetes $[7,12]$.

LTA may also be involved in the pathophysiology or pathogenesis of insulin-resistant disorders, since the IVS1+ 90ag polymorphism of LTA was reported to be associated with hypertriglyceridaemia in 61 diet-treated type 2 diabetic patients [13], and with fasting glycaemia and circulating lipid variables in 62 non-obese Caucasian subjects [14]. However, the results of another study of 17 lean and 21 obese subjects failed to support this finding [15]. Recently, a Japanese genome-wide case-control study investigated 65,671 genebased SNP markers in 1,133 patients with myocardial infarction and 1,006 control subjects [6]. Analysis of the data using a recessive genetic model revealed that functional SNPs in the $L T A$, including the IVS1+90ag polymorphism and the T60N polymorphism, were associated with increased susceptibility to myocardial infarction. This finding has since been replicated in another Japanese case-control association study that included 477 men with myocardial infarction and 372 control subjects [16]. Similarly, a South Korean study of 294 cases and 581 control subjects reported an association between the IVS1+90ag SNP and cerebral infarction [17]. Conversely, a recent Japanese study that included approximately 3,689 subjects failed to demonstrate an association between the polymorphism and myocardial infarction [18]. However, analysis of the data in a recessive genetic model revealed an association between the $\mathrm{T} 60 \mathrm{~N}$ polymorphism and type 2 diabetes, both in men with myocardial infarction and in control subjects without myocardial infarction [18]. Interestingly, obesity has been linked to DNA markers in the vicinity of the TNF- $\alpha$ locus [19]. The potential involvement of the LTA locus in the pathogenesis of type 2 diabetes and obesity is further supported by evidence suggesting that the innate immune system and proinflammatory cytokines con- tribute to the aetiology of certain subtypes of obesity and type 2 diabetes [20].

Based on these findings, the present study aimed to examine whether the functional and common LTA variant at codon 60 in its homozygous form is associated with type 2 diabetes mellitus and other phenotypes of the metabolic syndrome among Danish Caucasian individuals.

\section{Subjects and methods}

Subjects The study involved two groups of subjects: (1) a group of type 2 diabetic patients recruited from the outpatient clinic at the Steno Diabetes Center (Gentofte, Denmark); and (2) the Inter99 cohort. The Inter99 study was a population-based, randomised, non-pharmacological intervention study on the prevention of cardiovascular disease. The study was performed at the Research Centre for Prevention and Health (Glostrup University Hospital, Glostrup, Denmark) and involved 6,514 Caucasian subjects $(6,164$ with OGTT data). Details of this cohort have previously been reported [21]. Some of the subjects were not included in the analyses due to missing genotype data. The results presented in the tables are for subjects with available genotype data.

The case-control study of type 2 diabetes comprised a total of 1,401 unrelated type 2 diabetic patients: 1,056 type 2 diabetic patients recruited from the outpatient clinic at the Steno Diabetes Center, and 345 type 2 diabetic patients recruited from the Inter99 study. Age- and gender-matched glucose-tolerant control subjects $(n=1,470$; mean age $[ \pm \mathrm{SD}]$ $54 \pm 4$ years, mean BMI $\left.[ \pm \mathrm{SD}] 26.1 \pm 4.0 \mathrm{~kg} / \mathrm{m}^{2}\right)$ were from the Inter99 cohort. Diabetes was diagnosed in accordance with the criteria adopted by the World Health Organization (WHO) in 1999 [22]. The basic characteristics of the type 2 diabetic patients (means \pm SD) were: age $57 \pm 11$ years, age at clinical diagnosis $51 \pm 11$ years, BMI $29.6 \pm 5.3 \mathrm{~kg} / \mathrm{m}^{2}$ and $\mathrm{HbA}_{1} \mathrm{c} 7.8 \pm 1.7 \%$. At recruitment, patients with one or more of the following were excluded: (1) diabetes due to known chronic pancreatitis, haemochromatosis, severe insulin resistance, MODY, or maternally inherited diabetes and deafness; (2) a family history of first degree relatives with type 1 diabetes; (3) a requirement for insulin within the first year after the diagnosis of diabetes; or (4) a fasting serum C-peptide level $\leq 150 \mathrm{pmol} / \mathrm{l}$. Among the patients with type 2 diabetes, 131 patients (70 men, 61 women) were aged 40 years or younger at diagnosis. This subgroup was termed 'early-onset type 2 diabetes', and the remaining group was termed 'late-onset type 2 diabetes'. The clinical and biochemical data for these groups of patients are presented in Table 1.

In the genotype-quantitative trait studies, the data for 5,630 non-diabetic Caucasian subjects from the Inter99 cohort were analysed. All Inter99 participants were evaluated for the presence of the metabolic syndrome according to WHO criteria [22]; those found to have no components of the metabolic syndrome qualified as control subjects $(n=1,752)$. 
Table 1 Clinical and biochemical data of 1,401 type 2 diabetic patients divided according to age at clinical diagnosis

\begin{tabular}{|c|c|c|c|}
\hline Parameter & $\begin{array}{l}\text { Diabetes } \\
\text { diagnosis } \\
\text { after } 40 \text { years }\end{array}$ & $\begin{array}{l}\text { Diabetes } \\
\text { diagnosis at } \\
\text { or before } \\
40 \text { years }\end{array}$ & $p$ value $^{\mathrm{a}}$ \\
\hline $\begin{array}{l}\text { Number of subjects } \\
\text { (men/women) }\end{array}$ & $1,270(775 / 495)$ & $131(70 / 61)$ & \\
\hline $\begin{array}{l}\text { Age at diagnosis } \\
\text { (years) }\end{array}$ & $53(48-60)$ & $36(32-39)$ & \\
\hline $\begin{array}{l}\text { Age at examination } \\
\text { (years) }\end{array}$ & $59(51-64)$ & $45(39-51)$ & \\
\hline $\begin{array}{l}\text { Receiving insulin } \\
\text { treatment }\end{array}$ & $17 \%$ & $26 \%$ & \\
\hline BMI $\left(\mathrm{kg} / \mathrm{m}^{2}\right)$ & $28.9(26.1-32.6)$ & $30.0(25.7-33.9)$ & 0.37 \\
\hline $\begin{array}{l}\text { Waist } \\
\text { circumference }(\mathrm{cm})\end{array}$ & $99(90-108)$ & $102(90-113)$ & 0.02 \\
\hline $\mathrm{HbA}_{1} \mathrm{c}(\%)$ & $7.4(6.5-8.7)$ & $8.2(6.8-9.3)$ & $<0.001$ \\
\hline $\begin{array}{l}\text { Fasting plasma } \\
\text { glucose }(\mathrm{mmol} / \mathrm{l})\end{array}$ & $8.4(7.0-11.0)$ & $9.8(7.7-13.7)$ & $<0.001$ \\
\hline $\begin{array}{l}\text { Fasting serum } \\
\text { C-peptide (pmol/1) }\end{array}$ & 727 (535-985) & 689 (438-940) & $<0.001$ \\
\hline
\end{tabular}

Data are presented as medians (interquartile ranges)

${ }^{\mathrm{a}}$ After adjustment for age, sex and BMI where appropriate using a general linear model

According to self-report data, all study participants were Danish Caucasians. Informed written and oral consent was obtained from all study participants. The studies were performed in accordance with the Declaration of Helsinki and were approved by the Ethical Committee of Copenhagen County.

Biochemical measurements Blood samples for assessment of biochemical variables were drawn in the morning after an overnight fast. Plasma glucose, serum-specific insulin (excluding des-31,32 proinsulin and intact proinsulin) and serum C-peptide were analysed using the standard methods employed at the Steno Diabetes Center. $\mathrm{HbA}_{1} \mathrm{c}$ levels were measured by ion-exchange HPLC (VARIANT Hemoglobin $\mathrm{A}_{1} \mathrm{c}$ Analyzer; Bio-Rad, Richmond, CA, USA); the normal range of levels assessed using this method is $4.1-6.4 \%$. Concentrations of plasma triglycerides, HDL cholesterol and serum total cholesterol were determined using the Triglycerides GPO-PAP method, the HDL Cholesterol Plus method and the Cholesterol CHOD-PAP method (Roche Diagnostics, Mannheim, Germany), respectively. The insulinogenic index was calculated as ( $30 \mathrm{~min}$ post-OGTT serum insulin [pmol/1] -fasting serum insulin [pmol/1])/30 min postOGTT plasma glucose $(\mathrm{mmol} / \mathrm{l})$. The homeostasis model assessment for insulin resistance (HOMA-IR) was calculated as (fasting plasma glucose $[\mathrm{mmol} / 1] \times$ fasting serum insulin $[\mathrm{pmol} / 1]) / 22.5$.

Genotyping Genomic DNA was isolated from human leucocytes using standard methods. The IVS1+90ag polymorphism (rs909253) and the T60N polymorphism (rs1041981) were genotyped using a chip-based matrix-assisted laser desorption/ionisation time-of-flight mass spectrometry (DNA MassARRAY; Sequenom, San Diego, CA, USA) analysis of PCR-generated primer extension products as described previously [23]. The success rate was $96 \%$, with no mismatches among 89 replicate samples.

Statistical analysis Linkage disequilibrium was estimated as $R^{2}$, and was calculated as described at http://www. ekstroem.com (last accessed December 2004). Fisher's exact test was applied to test for significant differences in allele frequencies and genotype distributions in the type 2 diabetes case-control study. Logistic regression analyses were used to evaluate associations with features of the metabolic syndrome between control subjects who had no components of the metabolic syndrome and cases with one or more components of that syndrome. In these analyses age and sex were used as covariates.

Phenotypic differences between genotypes among glucose-tolerant subjects and type 2 diabetic patients were tested using a general linear model that included sex and genotype as fixed factors, and age and BMI as covariates if appropriate. For genotype-quantitative trait studies, the normal distribution of each trait was tested, and logarithmic transformation was performed if needed. Results provided as $p_{\text {recessive }}$ values refer to comparison of the $T / T$ and $T / N$ genotype groups combined with the $N / N$ genotype group. A $p$ value less than 0.05 was considered statistically significant. All analyses were performed using the Statistical Package for Social Science for Windows, Version 12.0 (SPSS, Chicago, IL, USA).

\section{Results}

The IVS1+90ag SNP and the T60N polymorphism of LTA were almost in complete linkage disequilibrium $\left(R^{2}=99.7 \%\right)$. The $A$ allele at position +90 was linked to the threonine allele (ACC) at codon 60, and the $+90 G$ variant was linked to the asparagine allele (AAC). Consequently, only data for the T60N polymorphism will be presented.

In the case-control study of type 2 diabetes, allele frequencies and genotype distributions were significantly different between the type 2 diabetic patients and the glucose-tolerant control subjects (Table 2). The asparagine at codon 60 (N60) was more frequent in cases than in glucose-tolerant control subjects (Table 2). The association between the $\mathrm{T} 60 \mathrm{~N}$ variant and type 2 diabetes was more pronounced among patients with early-onset (diagnosis $\leq 40$ years) type 2 diabetes (for patients with early-onset type 2 diabetes vs glucose-tolerant control subjects: $N / N$ genotype 21.4 vs $12.0 \%, p=0.004$; and minor allele frequency [MAF] $42.0 \%[95 \% \mathrm{CI} 36.0-48.0] \mathrm{vs}$ $35.0 \%$ [95\% CI 33.3-36.8], $p=0.026$ ) (Table 2).

Based on simulation studies, it was estimated that the present study had more than $90 \%$ power to detect a relative risk of 1.2 for an association with type 2 diabetes using a co-dominant model, and $45 \%$ power applying a recessive model. 
Table 2 Genotype distribution and allele frequencies of the T60N polymorphism of LTA in the total group of type 2 diabetic patients, in glucose-tolerant control subjects, and in a subgroup of type 2 diabetic patients with early-onset disease

\begin{tabular}{|c|c|c|c|c|c|c|c|}
\hline Genotype & $\begin{array}{l}\text { Glucose-tolerant } \\
\text { control subjects }\end{array}$ & $\begin{array}{l}\text { All type } 2 \\
\text { diabetic subjects }\end{array}$ & $p$ Value & OR $(95 \% \mathrm{CI})^{\mathrm{a}}$ & $\begin{array}{l}\text { Early-onset type } 2 \\
\text { diabetic subjects }\end{array}$ & $p$ value & OR $(95 \% \mathrm{CI})^{\mathrm{a}}$ \\
\hline $\begin{array}{l}\text { Number of } \\
\text { subjects } \\
\text { (men/women) }\end{array}$ & $1,470(882 / 588)$ & $1,401(845 / 556)$ & & & $131(70 / 61)$ & & \\
\hline$T / T$ & $617(42.0 \%)$ & $554(39.5 \%)$ & & & $49(37.4 \%)$ & & \\
\hline$T / N$ & $676(46.0 \%)$ & $643(45.9 \%)$ & & & $54(41.2 \%)$ & & \\
\hline$N / N$ & $177(12.0 \%)$ & $204(14.6 \%)$ & $0.048^{\mathrm{b}}$ & $1.24(1.00-1.55)$ & $28(21.4 \%)$ & $0.004^{\mathrm{b}}$ & $1.99(1.27-3.10)$ \\
\hline MAF & $35.0(33.3-36.8)$ & $37.5(35.7-39.3)$ & $0.051^{\mathrm{c}}$ & & $42.0(36.0-48.0)$ & $0.026^{\mathrm{c}}$ & \\
\hline
\end{tabular}

The genotype data show the number of subjects with each genotype (\% of each group), while the MAF data are percentages ( $95 \% \mathrm{CI})$. All genotype groups were in Hardy-Weinberg equilibrium

${ }^{a}$ For ' $N / N$ ' vs ' $T / N$ and $T / T$ '

${ }^{\mathrm{b}} p$ values are for comparison of the genotype distribution in diabetic patients with that in control subjects using a recessive model (' $T / T$ and $T / N$ ' to ' $N / N$ ')

${ }^{c} p$ values are for comparison of the allele frequencies in diabetic patients with those in control subjects

Compared with patients with late-onset diabetes, those with early-onset diabetes had slightly but significantly lower fasting serum C-peptide levels ( $5 \%$ decrease in median value) and poorer glycaemic regulation at enrolment (Table 1).

The results of the genotype-quantitative trait association study, which was performed in the 5,630 non-diabetic subjects from the Inter 99 cohort, revealed that the $N / N$ genotype of the $\mathrm{T} 60 \mathrm{~N}$ variant was associated with a slight but significant $(p=0.009)$ increase in waist circumference (Table 3 ). However, this finding may be spurious, since the difference is weak and the $N / N$ genotype was not found to be related to any other indices of obesity. In addition, the apparent effects of the variant on WHR and fasting serum HDL cholesterol levels disappeared when the results were cor-

Table 3 Clinical and biochemical data of middle-aged non-diabetic Caucasian subjects divided according to their genotype of the T60N polymorphism of $L T A$

\begin{tabular}{|c|c|c|c|c|}
\hline Parameter & $T / T$ & $T / N$ & $N / N$ & $\begin{array}{l}p_{\text {recessive }} \\
\text { value }^{\text {a }}\end{array}$ \\
\hline Number of subjects (men/women) & $2,306(1,123 / 1,183)$ & $2,597(1,275 / 1,322)$ & $727(364 / 366)$ & \\
\hline Age (years) & $45(40-50)$ & $45(40-50)$ & $45(40-50)$ & \\
\hline BMI $\left(\mathrm{kg} / \mathrm{m}^{2}\right)$ & $25.4(23.0-28.2)$ & $25.4(23.1-28.3)$ & $25.6(23.0-28.3)$ & 0.63 \\
\hline Waist circumference $(\mathrm{cm})$ & $85(76-94)$ & $86(76-94)$ & $86(76-95)$ & 0.009 \\
\hline WHR & $0.850(0.79-0.92)$ & $0.851(0.79-0.91)$ & $0.859(0.79-0.92)$ & 0.009 \\
\hline Fasting plasma glucose $(\mathrm{mmol} / \mathrm{l})$ & $5.4(5.1-5.8)$ & $5.4(5.1-5.8)$ & $5.4(5.1-5.8)$ & 0.64 \\
\hline $\begin{array}{l}\text { Incremental AUC-glucose } \\
(\mathrm{min} \cdot \mathrm{pmol} / \mathrm{l})\end{array}$ & $201(127-279)$ & $203(126-282)$ & $206(127-286)$ & 0.80 \\
\hline Fasting serum insulin (pmol/l) & $34(23-50)$ & $34(24-49)$ & $33(23-49)$ & 0.51 \\
\hline $\begin{array}{l}\text { Incremental AUC-insulin } \\
(\mathrm{min} \cdot \mathrm{pmol} / \mathrm{l})\end{array}$ & $18,705(13,170-27,285)$ & $18,585(13,050-26,940)$ & $18,360(13,046-26,348)$ & 0.76 \\
\hline Insulinogenic index for insulin & $25.3(17.3-37.4)$ & $24.7(17.1-36.8)$ & $24.5(17.4-35.8)$ & 0.62 \\
\hline Fasting serum C-peptide (pmol/l) & $523(408-683)$ & $524(413-692)$ & $521(414-696)$ & 0.68 \\
\hline $\begin{array}{l}\text { Incremental AUC-C-peptide } \\
(\mathrm{min} \cdot \mathrm{pmol} / \mathrm{l})\end{array}$ & $153,443(121,444-193,856)$ & $152,505(121,380-152,505)$ & $154,935(119,895-194,970)$ & 0.83 \\
\hline Insulinogenic index for C-peptide & $161(119-216)$ & $157(120-212)$ & $160(117-212)$ & 0.65 \\
\hline Fasting serum cholesterol $(\mathrm{mmol} / \mathrm{l})$ & $5.4(4.8-6.2)$ & $5.4(4.8-6.1)$ & $5.4(4.7-6.2)$ & 0.76 \\
\hline $\begin{array}{l}\text { Fasting serum HDL cholesterol } \\
(\mathrm{mmol} / \mathrm{l})\end{array}$ & $1.40(1.16-1.69)$ & $1.39(1.15-1.66)$ & $1.38(1.12-1.65)$ & 0.06 \\
\hline $\begin{array}{l}\text { Fasting serum triglycerides } \\
(\mathrm{mmol} / \mathrm{l})\end{array}$ & $1.0(0.8-1.5)$ & $1.0(0.8-1.5)$ & $1.1(0.8-1.5)$ & 0.41 \\
\hline HOMA-IR & $8.0(5.5-12.4)$ & $8.2(5.6-12.3)$ & $8.0(5.5-12.1)$ & 0.49 \\
\hline Systolic BP (mmHg) & $127(118-138)$ & $129(119-139)$ & $127(117-140)$ & 0.85 \\
\hline Diastolic BP (mmHg) & $80(75-95)$ & $80(75-90)$ & $80(73-90)$ & 0.70 \\
\hline
\end{tabular}

Data are presented as medians (interquartile ranges)

a $p$ value for comparison of ' $T / T$ and $T / N$ ' with ' $N / N$ ' after adjustment for age, sex and BMI where appropriate 
rected for multiple testing. The T60N polymorphism was not associated with fasting or post-load plasma glucose, serum insulin levels, or insulin resistance as estimated by HOMA-IR. No genotype effect on fasting serum lipids was observed (Table 3 ).

In the case-control studies of features of the metabolic syndrome in the Inter99 cohort, the T60N variant was not directly associated with the metabolic syndrome as defined by the 1999 WHO criteria (Table 4). However, the genotype distribution of the T60N variant was significantly different between subjects with one or more components of the metabolic syndrome and the subjects in the control group who were free of any component of the metabolic syndrome (Table 4). In line with the findings of the large diabetes case-control study, the frequency of the $N / N$ genotype tended to be higher among patients with type 2 diabetes in the Inter99 cohort than among subjects in the control group ( 14.8 vs $11.4 \% ; p=0.09)$. A similar tendency was observed when subjects without any features of the metabolic syndrome were compared with subjects exhibiting a specific component of the metabolic syndrome, including impaired glucose regulation, hypertension, dyslipidaemia and obesity (Table 4). When cases with type 2 diabetes, IGT or IFG were excluded from the analyses, the associations between the $N / N$ genotype and the individual components were even more marked (for cases vs controls: hypertension 13.5 vs $11.4 \%, p=0.06$; dyslipidemia 14.8 vs $11.4 \%, p=0.008$; and obesity 14.1 vs $11.4 \%, p=0.05$ ) (data not shown).

\section{Discussion}

Increasing evidence indicates that the innate immune system and proinflammatory cytokines are involved in pancreatic beta cell failure and impaired insulin action in patients with common forms of type 2 diabetes [20, 24, 25]. In addition, the results of analyses using a recessive genetic model have suggested that variations in LTA contribute to the pathogenesis of genetically complex diseases such as type 1 diabetes $[7,12]$, myocardial infarction $[6,16]$ and cerebral infarction [17]. Based on these findings, the aim of the present study was to test the hypothesis that $L T A$ variants are involved in the pathogenesis of phenotypes of the metabolic syndrome, including common subtypes of type 2 diabetes.

Recessive inheritance model analysis revealed that the functional $\mathrm{T} 60 \mathrm{~N}$ variant and the tightly linked functional IVS1+90ag polymorphism are associated with type 2 diabetes in Caucasian individuals. Since the submission of this paper, comparable findings have been reported by Yamada et al. [18] who examined the same LTA variants in a Japanese study population. In this study of 161 men with type 2 diabetes and 832 non-diabetic control subjects, the investigators demonstrated a significant association between the N/NLTA genotype and diabetes (odds ratio [OR]= 1.36). Similar results were obtained when the LTA genotypes of 515 type 2 diabetic men with previous myocardial infarction were compared with those of 978 non-diabetic men who had also experienced a myocardial infarction [18]. These results suggest that previously observed associations between $L T A$ variants and myocardial infarction $[6,16]$ may in part be secondary to associations between LTA genotypes

Table 4 Genotype frequency of the T60N polymorphism in LTA according to the 1999 WHO-defined metabolic syndrome components among the middle-aged Caucasian subjects of the Inter99 cohort

\begin{tabular}{|c|c|c|c|c|c|c|c|c|c|}
\hline Genotype & $\begin{array}{l}\text { Control } \\
\text { subjects }\end{array}$ & $\begin{array}{l}\text { Impaired } \\
\text { glucose } \\
\text { regulation }\end{array}$ & $\begin{array}{l}\text { Insulin } \\
\text { resistance }\end{array}$ & Hypertension & Dyslipidaemia & $\begin{array}{l}\text { Indices of } \\
\text { obesity }\end{array}$ & Microalbuminuria & $\begin{array}{l}\text { One or more } \\
\text { components } \\
\text { of the } \\
\text { metabolic } \\
\text { syndrome }\end{array}$ & $\begin{array}{l}\text { Metabolic } \\
\text { syndrome } \\
\text { as defined } \\
\text { by the } \\
1999 \text { WHO } \\
\text { criteria }\end{array}$ \\
\hline $\begin{array}{l}\text { Number } \\
\text { of } \\
\text { subjects } \\
\text { (men/ } \\
\text { women) }\end{array}$ & $\begin{array}{l}1,752 \\
(514 / 1,238)\end{array}$ & $\begin{array}{l}1,541 \\
(913 / 628)\end{array}$ & $\begin{array}{l}1,545 \\
(859 / 686)\end{array}$ & $\begin{array}{l}2,443 \\
(1,452 / 991)\end{array}$ & $\begin{array}{l}1,562 \\
(1,002 / 560)\end{array}$ & $\begin{array}{l}2,594 \\
(1,752 / 842)\end{array}$ & $169(75 / 94)$ & $\begin{array}{l}4,425 \\
(2,538 / 1,887)\end{array}$ & $\begin{array}{l}1,284 \\
(869 / 415)\end{array}$ \\
\hline$T / T$ & $718(41.0)$ & $629(40.8)$ & $635(41.1)$ & $987(40.4)$ & $638(40.8)$ & $1,047(40.4)$ & $67(39.6)$ & $1,794(40.5)$ & $530(41.3)$ \\
\hline$T / N$ & $834(47.6)$ & $701(45.5)$ & $717(46.4)$ & $1,128(46.2)$ & $712(45.6)$ & $1,185(45.7)$ & $83(46.1)$ & $2,026(45.8)$ & 589 (45.9) \\
\hline$N / N$ & $200(11.4)$ & $211(13.7)$ & $193(12.5)$ & $328(13.4)$ & $212(13.6)$ & $362(14.0)$ & $19(11.2)$ & $605(13.7)$ & 165 (12.9) \\
\hline MAF & $\begin{array}{l}35.2 \\
(33.6-36.8)\end{array}$ & $\begin{array}{l}36.4 \\
(34.7-38.1)\end{array}$ & $\begin{array}{l}35.7 \\
(34.0-37.4)\end{array}$ & $\begin{array}{l}36.5 \\
(35.2-37.9)\end{array}$ & $\begin{array}{l}36.4 \\
(34.7-38.1)\end{array}$ & $\begin{array}{l}36.8 \\
(35.5-38.1)\end{array}$ & $\begin{array}{l}35.8 \\
(30.7-40.9)\end{array}$ & $\begin{array}{l}36.6 \\
(35.6-37.6)\end{array}$ & $\begin{array}{l}35.8 \\
(33.9-37.6)\end{array}$ \\
\hline $\begin{array}{c}p_{\text {recessive }} \\
\text { value }\end{array}$ & - & 0.13 & 0.39 & 0.08 & 0.05 & 0.07 & 0.94 & 0.03 & 0.37 \\
\hline
\end{tabular}

The genotype data show the number of subjects with each genotype (\% of each group), while the MAF data are percentages $(95 \% \mathrm{CI})$. Control subjects were individuals from the Inter99 cohort with no components of the metabolic syndrome. All genotype groups were in Hardy-Weinberg equilibrium. The $p$ values are for comparison of the genotype distribution in cases for each component with that in control subjects with no components of the metabolic syndrome using a recessive model (' $T / T$ and $T / N$ ' to ' $N / N$ ') with adjustment for sex and age 
and diabetes. This interpretation of the data is consistent with the results of a study demonstrating that the LTA variants were not related to the risk of coronary artery disease or myocardial infarction in a German population [26]. Walton et al. [27] also failed to demonstrate a direct association between variations in LTA and myocardial infarction in a large population-based study involving 15,800 subjects. However, the same authors have shown that the LTA polymorphisms are significant predictors of CHD [27].

Taken together, the available literature suggests that $L T A$ may belong to a group of genes that confer susceptibility to risk factors for myocardial infarction, such as diabetes and other features of the metabolic syndrome, but do not directly (i.e. beyond the impact on conventional risk factors) contribute to myocardial infarction. The results of our present studies of associations between the LTA variants and the components of the metabolic syndrome support this hypothesis. When subjects in the Inter99 cohort were stratified according to the presence of one or more components of the metabolic syndrome as defined by the 1999 WHO criteria, the frequency of the $N / N$ genotype was significantly higher among subjects with one or more components of the metabolic syndrome than among subjects with no features of this syndrome. Furthermore, our post hoc analyses of each of the components of the metabolic syndrome revealed trends in the same direction with respect to hypertension, dyslipidaemia and obesity, and these effects were even more marked when subjects with impaired glucose regulation were excluded from the analyses.

The effects of variations in LTA on plasma glucose and serum lipid levels have yet to be conclusively determined. A recent Czech study of 113 healthy subjects revealed associations between the $\mathrm{NcoI}$ polymorphism of LTA and fasting levels of plasma glucose and serum lipids [14]. In contrast, in a study of 17 lean and 21 obese Spanish subjects, it was revealed that the same LTA SNP was not associated with serum lipids, plasma glucose or insulin resistance [15]. This finding is in agreement with our results, which revealed no direct associations between the LTA SNPs and pre-diabetic quantitative traits in 5,630 nondiabetic subjects from the Inter99 cohort. Given that the effects of $L T A$ variants on glucose and lipid metabolism are partly mediated through the TNF- $\alpha$ receptor-mediated pathway, these discrepancies could be due to the presence of variants in $T N F-\alpha$ and/or TNFAR genes in different populations. In this respect, previous reports of associations between $T N F-\alpha$ variants and type 2 diabetes are of particular interest [28]. In future studies of genetic epidemiology in non-diabetic individuals it will be relevant to compare the combined effect of variations in TNF- $\alpha, T N F A R$ and LTA not only on circulating cytokine levels, but also on prediabetic quantitative traits such as insulin secretion, insulin resistance, serum lipids and body composition.

Although the present study revealed only a weak association between the homozygous form of the variant and type 2 diabetes $(\mathrm{OR}=1.24)$, due to the relatively common frequency of this genotype, this is equivalent to a population attributable risk of approximately $3 \%$.
Interestingly, when the diabetic patients in our study were stratified according to age at clinical diagnosis, the prevalence of the N/N LTA genotype was considerably higher in patients with early-onset diabetes than in patients with late-onset diabetes (21.4 vs $14.6 \%$ ). Comparison of the clinical phenotypes of the two subgroups of type 2 diabetic patients at enrolment revealed that patients with early-onset diabetes had significantly lower fasting levels of serum C-peptide and poorer glycaemic regulation (as estimated from levels of $\mathrm{HbA}_{1} \mathrm{c}$ and fasting plasma glucose). Furthermore, a higher number of these patients received insulin treatment. In several respects the phenotype of the present subgroup of early-onset type 2 diabetic patients is similar to the clinical characteristics associated with latent autoimmune diabetes in adults (LADA), including earlier age of diabetes onset, diminished basal serum Cpeptide level, higher frequency of insulin treatment, and a poorer glycaemic response to therapy with oral hypoglycaemic drugs [29]. Moreover, LADA may typically account for approximately $10 \%$ of clinically diagnosed cases of type 2 diabetes among Caucasian individuals; indeed in the present study patients with early-onset diabetes represented $9.4 \%$ of the total group of diabetic patients [29]. Obviously, it will be relevant in future studies to examine patients with subtypes of type 2 diabetes known to be strongly associated with the N/N LTA genotype for the presence of markers of autoimmune pancreatic beta cell destruction, such as circulating autoantibodies to GAD65 or to islet cell cytoplasm. It should be noted that the present subgroup of patients with early-onset diabetes deviated from the typical LADA presentation in one respect. In most cases, LADA patients are reported to have a leaner phenotype than those with non-autoimmune-related diabetes [29]; however, according to BMI and waist circumference values, patients in the early-onset subgroup were at least as overweight or obese as those with late-onset diabetes.

In conclusion, among Caucasians, variations in LTA are associated with an increased risk of type 2 diabetes $(\mathrm{OR}=1.24)$ and other features of the metabolic syndrome. The diabetogenic effect of $L T A$ was even more pronounced in patients with early-onset type 2 diabetes.

Acknowledgements The authors thank B. Thorsteinsson for collecting the data for some of the type 2 diabetic patients; A. Forman, I. L. Wantzin and M. Stendal for dedicated and careful technical assistance; and Grete Lademann for secretarial support. The study was supported by the Danish Medical Research Council, the Danish Diabetes Association and European Economic Community grants (BMH4-CT98-3084 and QLRT-CT-1999-00546).

\section{References}

1. Gray PW, Aggarwal BB, Benton CV et al (1984) Cloning and expression of cDNA for human lymphotoxin, a lymphokine with tumour necrosis activity. Nature 312:721-724

2. McDevitt H, Munson S, Ettinger R, Wu A (2002) Multiple roles for tumor necrosis factor-alpha and lymphotoxin alpha/ beta in immunity and autoimmunity. Arthritis Res 4(Suppl 3): S141-S152 
3. Nedwin GE, Naylor SL, Sakaguchi AY et al (1985) Human lymphotoxin and tumor necrosis factor genes: structure, homology and chromosomal localization. Nucleic Acids Res 13: 6361-6373

4. Aggarwal BB, Eessalu TE, Hass PE (1985) Characterization of receptors for human tumour necrosis factor and their regulation by gamma-interferon. Nature 318:665-667

5. Messer G, Spengler U, Jung MC et al (1991) Polymorphic structure of the tumor necrosis factor (TNF) locus: an NcoI polymorphism in the first intron of the human TNF-beta gene correlates with a variant amino acid in position 26 and a reduced level of TNF-beta production. J Exp Med 173:209-219

6. Ozaki K, Ohnishi Y, Iida A et al (2002) Functional SNPs in the lymphotoxin-alpha gene that are associated with susceptibility to myocardial infarction. Nat Genet 32:650-654

7. Pociot F, Briant L, Jongeneel CV et al (1993) Association of tumor necrosis factor (TNF) and class II major histocompatibility complex alleles with the secretion of TNF-alpha and TNF-beta by human mononuclear cells: a possible link to insulin-dependent diabetes mellitus. Eur J Immunol 23:224231

8. Spies T, Blanck G, Bresnahan M, Sands J, Strominger JL (1989) A new cluster of genes within the human major histocompatibility complex. Science 243:214-217

9. Carroll MC, Katzman P, Alicot EM et al (1987) Linkage map of the human major histocompatibility complex including the tumor necrosis factor genes. Proc Natl Acad Sci U S A 84:85358539

10. Todd JA, Bell JI, McDevitt HO (1987) HLA-DQ beta gene contributes to susceptibility and resistance to insulin-dependent diabetes mellitus. Nature 329:599-604

11. Lie BA, Todd JA, Pociot F et al (1999) The predisposition to Type 1 diabetes linked to the human leukocyte antigen complex includes at least one non-class II gene. Am J Hum Genet 64: 793-800

12. Feugeas JP, Caillens H, Poirier JC, Charron D, Marcelli-Barge A, Wautier JL (1997) Influence of metabolic and genetic factors on tumour necrosis factor-alpha and lymphotoxin-alpha production in insulin-dependent diabetes mellitus. Diabetes Metab 23:295-301

13. Vendrell J, Gutierrez C, Pastor R, Richart C (1995) A tumor necrosis factor-beta polymorphism associated with hypertriglyceridemia in non-insulin-dependent diabetes mellitus. Metab Clin Exp 44:691-694

14. Kankova K, Marova I, Jansen EHJM, Vasku A, Jurajda M, Vacha J (2002) Polymorphism Ncol in tumor necrosis factor beta is associated with fasting glycemia and lipid parameters in healthy non-obese Caucasian subjects. Diabetes Metab 28:231237

15. Fernandez-Real JM, Gutierrez C, Ricart W et al (1997) The TNF-beta gene NcoI polymorphism is not associated with hypertriglyceridemia or insulin resistance in lean and obese subjects. Biochem Biophys Res Commun 236:829-832
16. Iwanaga $\mathrm{Y}$, Ono K, Takagi S et al (2004) Association analysis between polymorphisms of the lymphotoxin alpha gene and myocardial infarction in a Japanese population. Atherosclerosis 172:197-198

17. Um JY, An NH, Kim HM (2003) TNF-alpha and TNF-beta gene polyrnorphisms in cerebral infarction. J Mol Neurosci 21:167-171

18. Yamada A, Ichihara S, Murase Y et al (2004) Lack of association of polymorphisms of the lymphotoxin alpha gene with myocardial infarction in Japanese. J Mol Med 82:477-483

19. Norman RA, Bogardus C, Ravussin E (1995) Linkage between obesity and a marker near the tumor necrosis factor alpha locus in Pima Indians. J Clin Invest 96:158-162

20. Dandona P, Aljada A, Bandyopadhyay A (2004) Inflammation: the link between insulin resistance, obesity and diabetes. Trends Immunol 25:4-7

21. Jorgensen T, Borch-Johnsen K, Thomsen TF, Ibsen H, Glumer C, Pisinger C (2003) A randomized non-pharmacological intervention study for prevention of ischaemic heart disease: baseline results Inter99. Eur J Cardiovasc Prev Rehabil 10:377-386

22. World Health Organization Study Group (1999) Report of a WHO consultation: part 1. Diagnosis and classification of diabetes mellitus. World Health Organization, Geneva

23. Buetow KH, Edmonson M, MacDonald R et al (2001) Highthroughput development and characterization of a genomewide collection of gene-based single nucleotide polymorphism markers by chip-based matrix-assisted laser desorption/ionization time-of-flight mass spectrometry. Proc Natl Acad Sci U S A 98:581-584

24. Hotamisligil GS (2003) Inflammatory pathways and insulin action. Int J Obes Relat Metab Disord 27:S53-S55

25. Hu FB, Meigs JB, Li TY, Rifai N, Manson JE (2004) Inflammatory markers and risk of developing type 2 diabetes in women. Diabetes 53:693-700

26. Koch W, Kastrati A, Bottiger C, Mehilli J, von Beckerath N, Schomig A (2001) Interleukin-10 and tumor necrosis factor gene polymorphisms and risk of coronary artery disease and myocardial infarction. Atherosclerosis 159:137-144

27. Walton B, Wilerson JT, Coresh J, Boerwinkle E (2003) Thrombospondin-2 and lymphotoxin-alpha gene variations predict coronary heart disease in a large prospective study. Circulation 108(Suppl IV):771

28. Kubaszek A, Pihlajamaki J, Komarovski V et al (2003) Promoter polymorphisms of the TNF-alpha (G-308A) and IL-6 (C-174G) genes predict the conversion from impaired glucose tolerance to type 2 diabetes: the Finnish diabetes prevention study. Diabetes 52:1872-1876

29. Naik RG, Palmer JP (2003) Latent autoimmune diabetes in adults (LADA). Rev Endocr Metab Disord 4:233-241 